\title{
Um Recorte Semiótico na Produção de Sentido: imagem em mídia impressa
}

\author{
Isaac Antonio Camargo
}

Doutor em Comunicação e Semiótica pela Pontifícia Universidade Católica de São Paulo (PUC-SP). Professor do Departamento de Artes da Universidade Estadual de Londrina. Autor de, entre outros livros, Reflexões sobre o pensamento fotográfico: pequena introdução às imagens e à fotografia. Londrina: Eduel, 1997. isaac_camargo@hotmail.com

\section{RESUMO}

Este trabalho aborda alguns aspectos relacionados à identidade das imagens, tomando-as por meio das qualidades sensíveis que as determinam, enquanto ocorrências, segundo os modos como são realizadas, tendo por meta investigar seu processo de significação tomando por referência teórica a Semiótica Discursiva.

PaLAVRAS-CHAVE: imagem; mídia impressa; Semiótica Discursiva.

\section{Abstract}

Abstract: This article discusses some aspects related to the identity of images, considering them through out the sensible qualities that determine those images as occurrences, according to the ways they are produced, having as aim to investigate their signification process taking as theoretical reference the Discoursive Semiotics.

KEY WORDS: image; press media; Discoursive Semiotics. 


\section{Um Recorte Semiótico na Produção de Sentido: imagem em mídia impressa}

\section{A ocorrência imagética}

Primeiramente faz-se necessário definir Imagem como uma manifestação sensível. Sua presença no mundo é dada pelas qualidades que a caracterizam, evidenciam e fazem dela uma ocorrência produtora de sentido. São diversos os sentidos que as imagens propõem, tal é a gama de informações que articulam, seja pela simples existência visível, onde sua instauração eidética a coloca como um campo significativo ou pelas relações que estabelece com outras áreas do conhecimento, proporcionando o desenvolvimento de outros discursos, inclusive, o surgimento de relações interdiscursivas em que novos conteúdos podem ser articulados.

A palavra Imagem, como a conhecemos, vem do latim: Imago e corresponde à idéia de semelhança que, por sua vez, teve origem no Grego Mimésis, correspondendo à idéia de imitação, o que em última instância, se refere a algo a que ela equivale, substitui ou simula, algo que está fora dela, no mundo e que, por conseqüência, não é ela própria.

Com o passar do tempo, entendeu-se que as imagens habitam o mundo, no contexto da cultura, do mesmo modo que outras construções culturais também o habitam. Os modos de observar e interpretar o mundo, segundo as diferentes ciências, são também meios de construir imagens do mundo, mesmo que estas imagens sejam mentais e não visuais.
Para efeito de aproximação, neste trabalho, vamos tomar a Imagem como uma unidade visual orgânica, manifesta e indivisível, apreendida na sua totalidade.

Voltando à etimologia, podemos tomar a via que nos dá o entendimento de que a imagem corresponde à idéia de semelhança, deduzimos então que ela é sinônimo de identidade ou de identificação com algo que exista anterior ou exterior a ela. Durante muito tempo foi justamente a busca pela semelhança que orientou o caminho da criação e uso das imagens, como também de suas leituras. O avanço dos sistemas de criação e distribuição das imagens no mundo, fez com que elas se desprendessem da relação de similaridade com o visível e se aproximasse das relações sociais e culturais que dão significação às imagens, assim, elas ficam mais próximas da constituição das narrativas, do que da simples descrição das coisas do mundo. Enquanto narrativas, elas se propõem a estabelecer diferentes diálogos com o mundo e não serem apenas representações dele. Portanto, as imagens passaram a falar e não apenas reproduzir ou documentar o visível, assim sendo, deixaram de espelhar o visível e passaram a apresentar o visível. Neste caso, a imagem é também promotora de discursos, passa a contar histórias, descrever ou falar a respeito de algo. Enquanto documento, ela é motivo ou motivação de boa parte da epopéia humana, acelerada pelo surgimento da fotografia, do cinema, da televisão e dos sistemas digitais. 
Nos seus primeiros tempos era uma ilusão do visível, que encantava e atraía, depois é a ilusão do cinético que movimenta e conduz os olhares pela magia da ação recriada nos fotogramas ou na animação digital.

Além da aparência que as imagens assumem, parecendo-se ou não com o que conhecemos no mundo, vamos entendê-las também por meio de sua manifestação sensível, ou seja, por meio das qualidades que apresenta, pelas estratégias que dispõe ou articula mediante os meios de sua construção plástica. Tomando por base a relação do ser humano com o mundo natural, é fácil notar que ele é apreendido por meio das qualidades sensíveis que o mundo possui, acessadas pelos sentidos.

Em relação ao campo da visualidade, uma estratégia comum à constituição das imagens, é o transladamento destas qualidades do mundo para elas e é, por meio das estratégias discursivas ou constitutivas, que estas qualidades se transformam no conjunto de referenciais plásticos ou visuais que são, por fim, identificados no modo de construir ou de configurar as imagens no contexto da cultura.

Para os estudos iconográficos, das imagens, estas qualidades assumem a função de valores plásticos, podendo ser entendidos sob três aspectos distintos: luminosos, espaciais e temporais. É deste modo que são discursivizados, ou seja, articulados e apreendidos no contexto social e entendidos no contexto cultural. A ocorrência e o modo de articulação destes valores também se constitui em sentido e não apenas a imitação daquilo que se vê no mundo.

Deste modo é possível falar de valores luminosos, espaciais e temporais. Os valores luminosos podem se referir à variação de intensidade da luz, portanto é possível falar de luz e sombra; podem ser referir à variação de freqüência, portanto, é possível falar de cor. Os valores espaciais se referem à dimensão e a profundidade, portanto dão conta da tridimensionalidade que temos no mundo. Quanto aos valores temporais podemos nos referir aos modos de observação do mundo, quer seja pelo deslocamento de algo no espaço, pelas marcas dos gestos numa obra, manifestos pelo fazer de um autor.

Por fim, ler imagens é descobrir como suas qualidades sensíveis ou seus valores plásticos significam no contexto do qual resultam ou no qual se inserem. Portanto, é possível restringir melhor o entendimento de imagem, considerando-a uma configuração visual de qualidades sensíveis, capaz de produzir significação. A partir daqui, é possível pensar na existência semiótica das imagens, portanto, para a semiótica discursiva, vamos entendê-las como textos.

\section{Semiótica e imagem}

Para a Semiótica discursiva toda manifestação capaz de significar é um texto, quer seja verbal, gestual ou imagético. Neste campo, a significação resulta da união de dois planos da linguagem: o Plano da Expressão e o Plano do Conteúdo.

O Plano da Expressão é a instância em que as qualidades sensíveis, as substâncias expressivas e demais elementos da linguagem assumem uma estrutura formal, nas diferentes manifestações apreendidas. $\mathrm{O}$ Plano do Conteúdo é o lugar em que nasce a significação, o lugar onde as variações e diferenças se manifestam por meio do ordenamento das idéias, conceitos e valores inerentes à cultura para realizar os efeitos de sentido necessários para o entendimento e compreensão do discurso em si. Portanto, o sentido, ou significado, se dá pelas 
combinatórias, pelas relações entre os dois planos e o contexto revelado por meio do próprio texto, ou seja, a partir de sua Enunciação, ou seja, como a imagem é constituída no intuito de realizar o sentido.

Em se tratando de imagens que ocorrem na mídia impressa, devemos observar que estas ocorrências não implicam apenas nas figuras iconográficas, mas também na articulação diagramática destas figuras com o todo da página. Estamos entendendo por mídia impressa, o conjunto de publicações, como jornais, revistas e livros que atuam na sociedade com vistas a coletar, editar e difundir informação por meio de um discurso verbo/visual.

Portanto, a análise recai sobre o Discurso, ou seja, sobre o Texto Manifesto, onde as idéias, valores e conteúdos são colocados em funcionamento na estrutura da linguagem ou da manifestação analisada, seja verbal, visual, sonora etc.

Por isso que, para entender como um Texto significa, é necessário analisar o Discurso (sua manifestação) considerando o encadeamento realizado para construí-lo e, a este encadeamento, podemos chamar de Percurso de Significação. O Percurso de Significação se refere à análise dos encadeamentos que ocorrem entre o Plano da Expressão e o Plano do Conteúdo, para descobrir de que modo o sentido se realiza, ou seja o quê, a quem e como o texto diz.

A manifestação, ou seja, a colocação em discurso, depende de sua realização por meio de uma ocorrência que transforme o virtual em real, é a partir daí que a vemos como Enunciação. A Enunciação pressupõe aquele que diz ou seja, o Enunciador que, por sua vez, incorpora duas instâncias do discurso: Enunciador e Enunciatário, (o que diz e a quem se diz). O Enunciador reúne os procedimentos discursivos, dando-lhe forma mediante os valores, argumentos e dispositivos da cultura configurando o discurso que carrega em si a significação. Para que se entenda o Percurso da Significação há que vê-lo de um modo acessível à compreensão, neste caso, ele é visto como uma Narrativa.

A Narrativa é o encadeamento de ocorrências formais, como uma seqüência ordenada, cujo objetivo é operar valores e conquistas com vistas à sanção dos sujeitos da enunciação que se realiza num programa. No Programa Narrativo é que o sujeito da narrativa assume um contrato, é manipulado para aquisição da competência necessária para a realização da performance e obtenção da sanção.

A manipulação consiste num compartilhamento de valores entre sujeitos, o que manipula e o que é manipulado. Há três tipos de manipulação: Provocação; Sedução; Intimidação e Tentação. É ainda na Narrativa que se encontram os modos de constituição das Pessoas, do Tempo e do Espaço, cujas estratégias dão-lhe veracidade.

A partir do momento em que consideramos a imagem como um texto manifesto, constituída por um plano de expressão e um plano de conteúdo, vamos observar como estas duas instâncias se apresentam numa imagem. É então possível, identificar na imagem, aquilo que chamamos de Narrativa? 


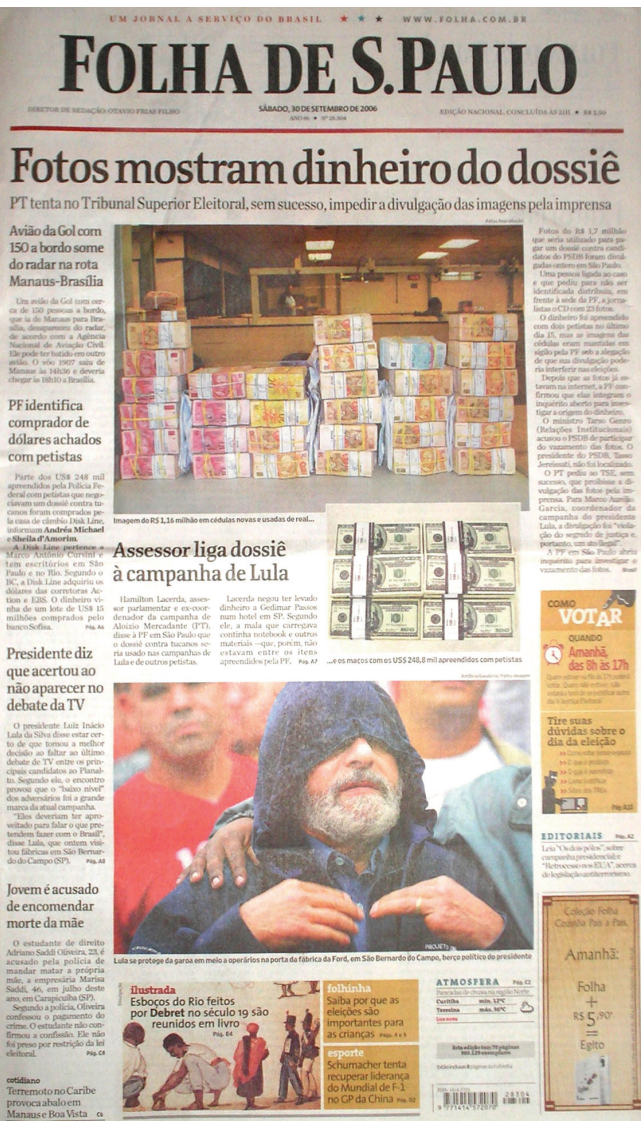

Folha de S. Paulo, 30 de setembro de 2006

Tomando como exemplo a página de rosto da Folha de S. Paulo, edição do dia 30 de setembro de 2006, vamos observar como que estes planos são realizados e de que modo o sentido é construído por meio de uma narrativa verbo/visual.

Pode-se dizer que o plano da expressão corresponde aos aspectos plástico-visuais da manifestação, ou seja, às qualidades sensíveis observadas por meio das substâncias de expressão usadas e dos modos como estas substâncias são articuladas na configuração da imagem como tal, neste caso, é possível observar que os aspectos sensíveis são manifestos por meio dos elementos plásticos identificáveis como: Luminosidade e Espacialidade, sendo que o efeito de
Temporalidade é produzido pelo percurso visual no campo diagramático, neste caso, constituído pelo todo da página do jornal.

No que diz respeito à luminosidade podemos analisar os valores tonais e cromáticos, e verificar como estes elementos aparentam na imagem as suas qualidades sensíveis. Aspectos iconográficos da página, as fotos e demais figuras que compõem o conjunto significante. Além das figuras, podemos entrever a estrutura gráfica da página com suas letras, fontes, tamanhos, manchetes, rubricas etc. Podem entrar também os elementos publicitários e chamadas para reportagens especiais, informativos e o próprio texto que, em colunas, ordena os caminhos do olhar.

Além disso, podemos ainda observar o que é revelado nas e pelas imagens, como também, o modo como se revela o conteúdo das imagens. Neste caso em especial, o foco da primeira página é a apreensão de valores de posse de auxiliares do presidente, em campanha, para compra de suposto dossiê sobre seu oponente, mostrado na foto na parte superior da página. A outra imagem, de tamanho igual à primeira está na parte inferior da página e mostra uma pessoa acompanhada/conduzida por outra que the apóia o ombro, pela aparência do rosto e da mão, conclui-se que é o presidente Lula, escoltado por assessores e segurança, coberto por um capuz que o esconde. Uma foto menor, maços de dólares, interliga as duas fotos maiores. Em baixo, pequenas imagens dão conta de outras questões de menor importância, já que o tamanho das imagens assim o diz. Pois, dimensão e posição no espaço definem o nível de importância das imagens na mídia impressa. Fotos grandes e letras grandes, posicionamento no alto da página são, comumente, indicadores de importância. 
Todos estes aspectos dão conta dos componentes estésicos destas informações que, na instância do conteúdo, deve se revelar como um componente do próprio sentido, ou seja, sua significação.

Tomando agora como referência o plano do conteúdo, podemos partir da observação de como, certos aspectos da configuração plástica, implicam, interferem ou explicitam o processo significativo. Em primeiro lugar podemos focar as estratégias da constituição da imagem em busca das estratégias de construção dos seus significados. Cabe ressaltar, que esta proposição é apenas analítica, já que plano de expressão e plano de conteúdo constituem uma só unidade, apenas distintos no contexto da análise, pois, no mundo natural, um e outro não se distinguem. Este é o caráter da semiótica discursiva, o desenvolvimento de uma metalinguagem para analisar as diferentes ocorrências textuais em busca da significação.

Neste caso o que se propõe como plano de conteúdo é a organização encadeada de imagens e texto. A manchete, posicionada logo abaixo da marca do jornal, diz: "Fotos mostram dinheiro do dossiê" seguida da rubrica: "PT tenta no superior tribunal eleitoral, sem sucesso, impedir a divulgação das imagens pela imprensa". As demais chamadas para o assunto dão conta do percurso do dinheiro e sua finalidade. Por meio deste processo cognitivo, baseado na associação de idéias, é possível deduzir que o dinheiro, de posse de petistas, era destinado a compra de um dossiê que comprometia o candidato de oposição ao presidente Lula. A imagem superior mostra o dinheiro todo, a imagem intermediária mostra dólares e a imagem inferior mostra o presidente em situação constrangedora, em razão da chuva daqueles dias, é obrigado a cobrir-se com um moletom de capuz, que lhe cobre a visão, esta imagem é facilmente associada às fotos de marginais que procuram esconder o rosto quando fotografados, logo, a relação entre o dinheiro da foto principal, e a imagem da foto de baixo, leva à apreensão do sentido de uma relação espúria entre o candidato e o dinheiro. Neste aspecto, em nenhum momento houve qualquer alusão explícita a esta relação, mas para bom entendedor, meia palavra e algumas imagens bastam.

Na Mídia Impressa, no jornal, por exemplo, lidamos com uma única Manifestação que une os dois tipos de Discursos, o verbal e o visual.

Embora o discurso verbal possua um tipo de estrutura, e o visual outro, os dois discursos constroem narrativas capazes de nos informar e produzir efeitos de sentido suficientes para nos convencer de algo ou nos revelar uma dada ocorrência no tempo e no espaço sem que tenhamos que fazer malabarismos extremos para entender o dito, neste caso, ao estudarmos a mídia impressa, não podemos tratar a imagem ou o verbo separadamente, devemos entendê-los em conjunto, pois o significado se dá na conjunção e não na disjunção entre estas duas instâncias sígnicas.

\section{Imagem e mídia impressa: Relações produtoras de sentido}

Sabemos, no contexto do jornalismo impresso, que a configuração imagética de suas páginas se constitui num discurso sincrético, este tipo de discurso pressupõe a interrelação de, pelo menos, duas instâncias discursivas na construção de um só significado. É o caso dos Objetos Noticiosos, que são utilizados na mídia impressa ou televisiva em que mais de uma estrutura de 
linguagem é operada na construção de sentido. Neste caso, diferentes elementos ou substâncias expressivas são ordenadas, organizadas, manipuladas para gerar competência e realizar performances, imagem, texto, som, movimento tudo isto pode ser utilizado pelo jornalismo televisivo, por exemplo, para construir uma só significação, é justamente a significação construída na relação entre os diferentes elementos significantes que produz cognição. Se observarmos cada um deles em separado, provavelmente, não teremos o mesmo efeito do que se observarmos o todo articulado e organizado.

Podemos dizer, grosso modo, que esta é uma relação onde as qualidades sensíveis das imagens são associadas às qualidades informativas da mídia, construídas verbalmente, quer seja no jornal impresso ou televisivo.

A produção de significação, com base na relação imagem e texto na mídia se constitui num todo manifesto, por isso, sua análise pode ser feita sob a égide do Sincretismo, ou seja, onde duas ou mais linguagens se unem para a realização de um só discurso. Portanto, podemos dizer que há um tipo de construção verbo/visual que é amparada pela estrutura imagética da página impressa, que podemos considerar a partir de sua estrutura diagramática, ou seja, o modo como é organizada a distribuição dos elementos significativos na página. Esta Articulação diagramática orientada pela presença verbo/ visual no contexto midiático assume a condição de narrativa, por meio da qual absorvemos o discurso usado para a distribuição da informação.

Deste modo é que se instaura o sujeito da enunciação. O sujeito é a instância da Enunciação que assume a organização do conteúdo informativo (destinador) e subsume a instância receptiva (destinatário). O sujeito é, ao mesmo tempo, aquele que diz e aquele que ouve, pois é constituído segundo os parâmetros de entendimento, condicionantes educacionais e sociais que amparam a cultura em que o jornal se manifesta. Aspectos da memória, históricos ou pessoais, relações entre os diferentes discursos das diferentes mídias são superpostos para construir sentido. Nem tudo é dado no texto, mas parte do que se constrói como sentido é recuperado por meio das vivências e memórias do destinatário, cujas ações são previstas antecipadamente pelo destinador.

Por exemplo, o lugar de onde se olha uma imagem, o ponto de observação constituído numa fotografia, se caracteriza como a posição do sujeito que enuncia, por meio desse olhar que as demais instâncias, tempo e espaço, se desenvolvem. Ângulo, profundidade, planos, iluminação, tudo isto é estratégia discursiva, dando a ver ou obliterando coisas que interessam ao significado. São justamente as estratégias de organização do espaço midiático que dependem de atualização por parte dos destinatários (leitores), para apreensão de suas mensagens e informações. O que implica, inclusive na condução do olhar, organizando e valorando os dados e informes que compõem a notícia e lhe dão significado.

Uma estratégia comum na mídia que se utiliza das imagens, é ordenar o sentido por meio da manipulação imagética ao instituir o que podemos chamar de sedução estésico/ cognitiva que resulta das concatenações, dos diálogos possíveis entre o texto e o contexto onde o investimento no sensível, como luzes, cores, formas, tipos gráficos, diagramas, imagens, gráficos, fotos etc. constituem um universo significante poderoso.

Além disso podemos destacar também o que chamaríamos de manipulação pelas 
falas, ou seja o uso das manchetes, das rubricas, dos títulos, das legendas e outros modos de construir significação a partir de estruturas frasais que orientam o destinatário para o raciocínio lógico/cognitivo dando-lhe a sensação de que foi ele quem construiu o sentido e não o resultado de um processo discursivo manipulatório. 